\title{
O fenômeno da desindustrialização: uma análise do caso paranaense no período 1990-2010
}

Renato Nataniel Wasques*

Resumo: O debate em torno do fenômeno da desindustrialização se intensificou no Brasil a partir de 2003 devido à apreciação cambial. Esse debate gerou argumentos favoráveis e desfavoráveis à tese de desindustrialização da economia brasileira. Nesta perspectiva, o presente artigo objetiva contribuir com o debate analisando se existem evidências de desindustrialização na economia paranaense no período 1990-2010, considerando o conceito de desindustrialização à luz da Teoria Econômica. Para tanto, são analisados os dados referentes à participação do emprego industrial e do valor adicionado da indústria de transformação paranaense no emprego total e no PIB do estado, respectivamente. Além disso, analisam-se os dados referentes às exportações paranaenses com o objetivo de verificar se ocorreu um processo de reprimarização.

Palavras-chave: Desindustrialização; Economia paranaense; Economia regional.

Classificação JEL: L6; O14; R11.

\footnotetext{
* Mestre em Teoria Econômica pela Universidade Estadual de Maringá (UEM). Professor da Faculdade do Noroeste Paranaense (FANP). Endereço eletrônico: renatowasques@gmail.com. 


\section{Introdução}

No decorrer da primeira década do século XXI, o debate em torno do "suposto" processo de desindustrialização da economia brasileira intensificouse devido à apreciação da moeda local. Neste contexto, foram elaborados argumentos favoráveis e desfavoráveis à tese de desindustrialização da economia brasileira.

No que se refere às Unidades da Federação, pouco ou nenhum trabalho tem sido realizado. Neste contexto, o presente artigo se justifica por apresentar uma análise do caso paranaense, ou seja, em motivar o debate em torno do fenômeno da desindustrialização ao nível regional. Dentro deste contexto, delimita-se o objetivo deste estudo, que consiste em verificar se existem evidências de desindustrialização na economia paranaense no período 1990-2010 considerando o conceito de desindustrialização à luz da Teoria Econômica.

Para que o objetivo proposto fosse alcançado, procurou-se contrapor o entendimento do processo de desindustrialização na Teoria Econômica ao desempenho recente da indústria paranaense, levando em conta, sobretudo, seu desempenho comercial.

Para tanto, o estudo divide-se em duas seções, além desta introdução e das considerações finais. Na primeira, busca-se apresentar o conceito de desindustrialização segundo a Teoria Econômica, bem como suas causas e efeitos. Na seção seguinte, realiza-se uma análise do caso paranaense buscandose evidenciar pistas em direção ao fenômeno da desindustrialização de uma Unidade da Federação.

\section{0 conceito de desindustrialização segundo a Teoria Econômica}

O conceito de desindustrialização foi apresentado por Rowthorn e Ramaswamy (1997,1999). Conforme esses autores, a desindustrialização consiste em uma redução persistente da participação do emprego industrial no emprego total. Mais recentemente, Tregenna (2009) reformulou esse conceito. Para a autora, a desindustrialização deve ser compreendida como uma redução persistente da participação do emprego industrial e do valor adicionado da indústria de transformação no emprego total e no PIB, respectivamente. 
Quanto às causas do processo de desindustrialização, Rowthorn e Ramaswamy $(1997,1999)$ enfatizam dois fatores. O primeiro refere-se ao aumento mais acelerado da produtividade do fator de produção trabalho na indústria do que no setor de serviços. $\mathrm{O}$ segundo fator interno diz respeito à mudança na relação entre a elasticidade de renda da demanda por bens manufaturados e serviços.

Compreendidos desta forma, os fatores internos sugerem que a desindustrialização das economias desenvolvidas não se apresenta como um fenômeno indesejável, mas como uma etapa natural de suas trajetórias de desenvolvimento econômico. Neste sentido, reportando-se aos estudos de Clark (1980) sobre a evolução da estrutura do emprego, Rowthorn e Ramaswamy (1997, 1999) mostram que nos estágios iniciais do desenvolvimento de uma economia, o setor primário é predominante. Porém, a medida que o desenvolvimento se aprofunda, os incrementos contínuos na renda per capita resultam em redução da demanda por alimentos, isto é, desencadeia deslocamentos da demanda de bens essencialmente agrícolas para bens manufaturados, dando início ao processo de industrialização. Entretanto, como o crescimento da produtividade do fator de produção trabalho no setor industrialé maior que no de serviços e, além disso, como a elasticidade de renda da demanda por manufaturados nas economias avançadas tende a ser inferior à unidade, a partir de um determinado nível de renda per capita, o emprego industrial perderia participação em relação ao emprego total e ocorreria também um deslocamento da demanda do setor industrial para o setor de serviços iniciando, assim, a fase de desindustrialização.

Além dos fatores internos, a desindustrialização também pode ser causada pela "doença holandesa" (dutch disease). Segundo Bresser-Pereira (2010), a descoberta de um determinado recurso natural escasso como, por exemplo, o petróleo, faria com que o país promovesse uma transferência de recursos de outras atividades para a sua extração e exportação. Como consequência da exportação dessa commodity, surgiria uma tendência de apreciação cambial que poderia impactar negativamente a competitividade do setor industrial, provocando, assim, o que os autores classificaram como desindustrialização prematura. Este caso de desindustrialização é considerado prejudicial às economias, pois é desencadeado em uma etapa precoce da trajetória de desenvolvimento econômico. 
Por fim, cabe ressaltar que a literatura sobre os efeitos do processo de desindustrialização não converge para um ponto consensual. Conforme Oreiro e Feijó (2010), os modelos neoclássicos de crescimento econômico, exógenos ou endógenos, não elegem um setor da economia como o mais representativo. Assim, uma unidade de valor adicionado na agricultura, na indústria ou no setor de serviços seria indiferente sobre o potencial de crescimento econômico de longo prazo, pois promoveria o mesmo impacto. Em contrapartida, a linha de pensamento heterodoxa afirma que a redução da participação do setor industrial no emprego e no valor adicionado pode reduzir o ritmo de crescimento das economias. Isso ocorreria pois a indústria é considerada o "motor do crescimento de longo prazo das economias capitalistas" (Oreiro; Feijó, 2010, p. 223).

A próxima seção deste artigo empregará o conceito de desindustrialização à luz da Teoria Econômica para verificar se a economia paranaense passou por um processo de desindustrialização no período 1990-2010.

\section{0 caso da economia paranaense}

Com o intuito de verificar se existem evidências de desindustrialização na economia paranaense, torna-se necessário apresentar a participação do emprego industrial em relação ao emprego total e a participação do valor adicionado da indústria de transformação paranaense no PIB do Paraná. Para tanto, o Gráfico 1 apresenta a evolução da participação percentual do emprego da indústria de transformação em relação ao emprego total na economia paranaense.

Conforme o conceito de desindustrialização criado por Rowthorn e Ramaswamy (1997, 1999), observa-se que a economia paranaense não passou por um processo de desindustrialização no período 1996-2010, pois não se percebeu uma queda persistente da participação do emprego industrial em relação ao emprego total no estado do Paraná. Observa-se que o percentual de pessoas ocupadas na indústria de transformação em relação ao emprego total cresceu gradualmente até o ano de 2007, desacelerando no biênio 2008-2009 e, a partir de 2010, estabilizando-se. Isso indica que a indústria de transformação paranaense não perdeu importância relativa como fonte geradora de emprego. 
Gráfico 1 - Participação percentual do emprego da indústria de transformação em relação ao emprego total no estado do Paraná (1996-2010)

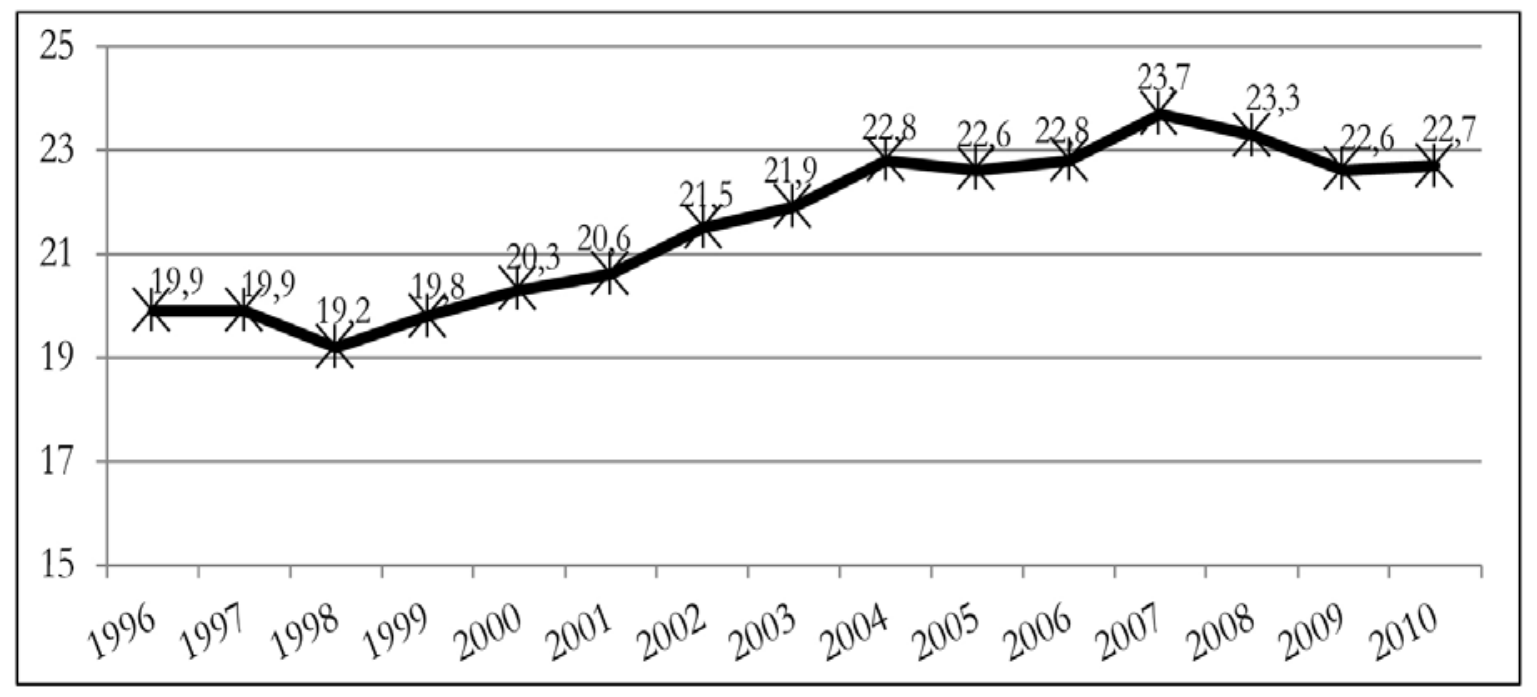

Fonte: Elaboração própria com base no IPARDES.

O comportamento do valor adicionado da indústria de transformação paranaense se revela por meio do Gráfico 2. Verifica-se que a participação percentual do valor adicionado da indústria de transformação em relação ao PIB do Paraná e do Brasil, respectivamente, vem declinando ao longo do tempo. No entanto, a participação relativa do valor adicionado da indústria de transformação paranaense superou a participação relativa do valor adicionado da indústria de transformação brasileira no triênio 1990-1992. A partir de 1993 desencadeou uma tendência de queda e, posteriormente, depois de 1998 começou a recuperar sua participação. Foi a partir do ano de 2001 que a participação do valor adicionado da indústria de transformação no PIB paranaense supera a brasileira, mantendo-se até o último ano em análise, conforme o Gráfico 2. Este fato indica que o dinamismo da economia paranaense era distinto e superior ao observado na economia brasileira na última década.

Com relação aos fatores causadores da perda de participação relativa do valor adicionado da indústria de transformação do Paraná no período 19931998, pode-se citar a abertura comercial e as medidas de políticas econômicas conduzidas para consolidar o processo de estabilização dos preços, como: juros elevados e apreciação cambial. Além disso, esse período fora caracterizado por várias crises financeiro-monetárias como, por exemplo, a crise mexicana (1995) e a crise russa (1997). Estes fatores exerceram influência sobre o desempenho industrial. 
Entretanto, com base neste período de redução da participação do valor adicionado da indústria de transformação paranaense, não é possível qualificar um processo de desindustrialização no estado, pois não se observou uma redução generalizada. Assim, “(...) apesar de a indústria de transformação paranaense ter passado por uma perda de sua relevância em termos relativos, com início na década de 90, esta é retomada a partir de 1998, voltando a ter uma representatividade de $27,11 \%$ em 2003 , contra $27,16 \%$ em 1985 , o que não caracterizaria um fenômeno de desindustrialização" (Scatolin, 2007, p. 114).

Gráfico 2 - Participação percentual do valor adicionado da indústria de transformação do Paraná e do Brasil em relação ao PIB do Paraná e do Brasil (1990-2008)

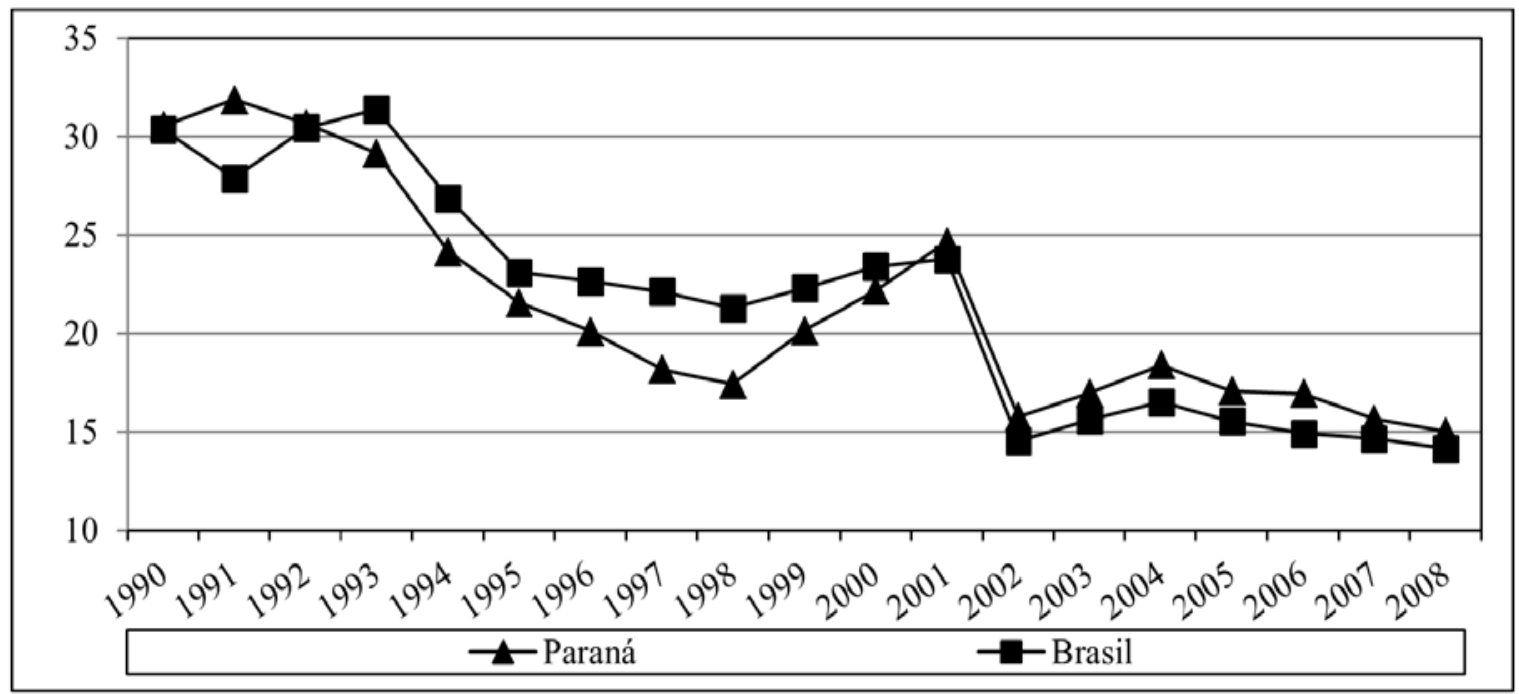

Fonte: Elaboração própria com base no IPEADATA.

Por fim, resta analisar o desempenho das exportações paranaenses. O objetivo dessa análise consiste em identificar se ocorreu um processo de reprimarização da pauta de exportações do Paraná a partir da segunda metade da década de 1990 e, consequentemente, se a economia paranaense fora contagiada pela "doença holandesa". Para tanto, são avaliados os dados referentes à participação relativa das exportações de produtos industriais e produtos não industriais, bem como os dados referentes à participação relativa das exportações por intensidade tecnológica.

A participação relativa das exportações de produtos industriais e produtos não industriais paranaenses no período 1996-2010 é evidenciada por meio do Gráfico 3. Identifica-se que a participação relativa das exportações de produtos industriais ao longo do período 1996-2010 oscilou em torno de 80\%, 
enquanto que a participação relativa das exportações de produtos não industriais manteve-se em torno de $20 \%$.

Observa-se que a partir de 2005 a participação relativa das exportações de produtos industriais vem decrescendo e a de produtos não industriais aumentando. Esse movimento pode ser consequência dos efeitos da política macroeconômica cujo alicerce, desde janeiro de 1999, tem sido o tripé superávit primário-metas de inflação-câmbio flutuante. Esse regime de política tem mantido a moeda doméstica apreciada e, consequentemente, desestimulando as exportações de produtos industriais. Identifica-se também que a participação relativa das exportações de produtos não industriais tem aumentado desde 2005. Esse aumento pode ser reflexo do aquecimento da demanda externa por commodities e da elevação dos preços das mesmas.

Gráfico 3 - Participação relativa das exportações de produtos industriais e produtos não industriais no Paraná (1996-2010)

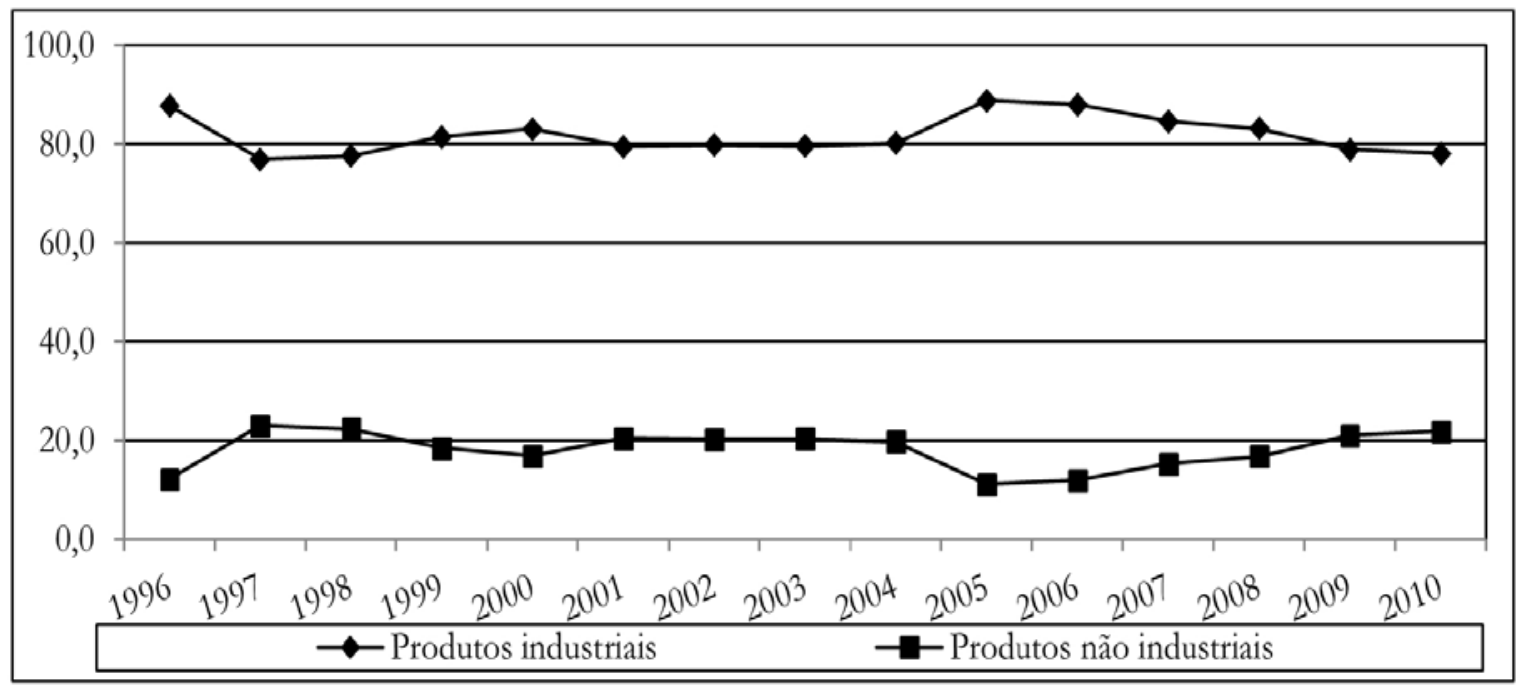

Fonte: Elaboração própria com base no MDIC (2011).

A participação relativa das exportações paranaenses por intensidade tecnológica, por sua vez, é apresentada por intermédio do Gráfico 4. Pode-se observar que a participação relativa das exportações de produtos da indústria de alta tecnologia e da indústria de média-baixa tecnologia manteve-se praticamente constante ao longo do período 1996-2010. Por outro lado, a participação relativa das exportações da indústria de baixa tecnologia e da indústria de média-alta tecnologia registrou certa volatilidade. Em 1996, as exportações da indústria de baixa tecnologia representavam $72,1 \%$ das exportações totais. Essa participação 
caiu para 49,2\% em 2010. A participação relativa das exportações da indústria de média-alta tecnologia, por sua vez, aumentou de 11,9\% em 1996 para 23,3\% em 2010.

Entre 1996 e 2010, a participação relativa das exportações paranaenses da indústria de alta tecnologia cresceu 0,5 pontos percentuais e, além disso, a participação relativa da indústria de média-alta intensidade tecnológica cresceu 11,4 pontos percentuais. Por outro lado, no mesmo período, as participações relativas das exportações paranaenses das indústrias de média-baixa e baixa intensidade tecnológica decresceram cerca de 21 pontos percentuais. Estas participações relativas sugerem que a economia paranaense, no período 19962010, aprofundou seu processo de industrialização em direção aos processos intensivos em tecnologia. Assim, não é possível afirmar que a pauta de exportações do Paraná passou por uma reprimarização.

Gráfico 4 - Participação relativa das exportações paranaenses por intensidade tecnológica no período 1996-2010

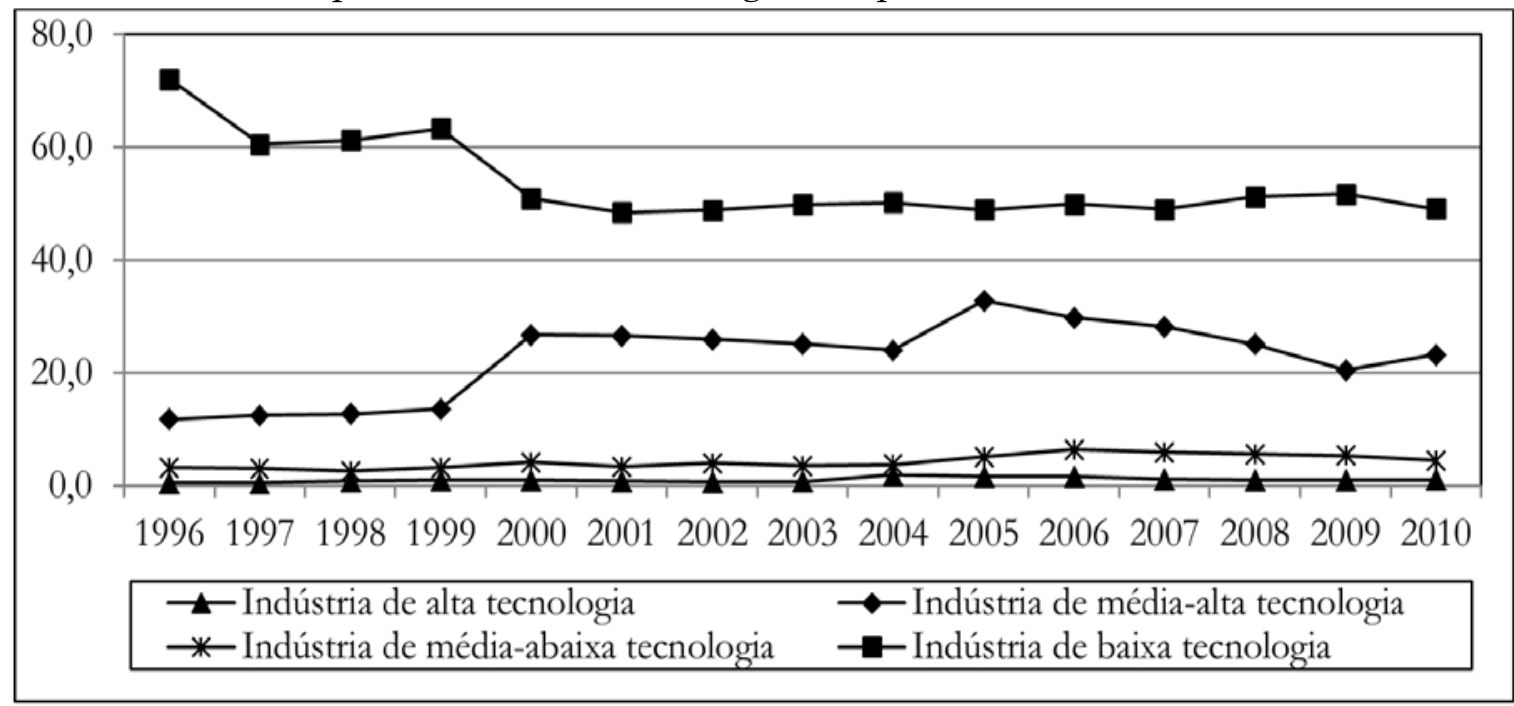

Fonte: Elaboração própria com base no MDIC (2011).

Levando-se em consideração o conceito ampliado de desindustrialização cunhado por Tregenna (2009) e, além disso, o conceito de "doença holandesa" discutido por Bresser-Pereira (2010), não se pode afirmar que a economia paranaense passou por um processo de desindustrialização no período 19902010. A análise dos dados estatísticos revela uma intensificação do processo de industrialização paranaense. Além disso, não se pode afirmar que a economia paranaense fora contagiada pela "doença holandesa" nos últimos vinte anos. 
A análise da composição da pauta exportadora do Paraná mostra um aumento da participação relativa das indústrias de alta e média-alta intensidade tecnológica.

\section{Considerações finais}

O presente artigo buscou identificar evidências de um processo de desindustrialização na economia paranaense. Para atingir esse objetivo, utilizouse o conceito de desindustrialização do ponto de vista da Teoria Econômica.

A análise dos dados não permitiu afirmar que a economia paranaense vem passando por um processo de desindustrialização, pois não se observou uma redução persistente da participação relativa do pessoal ocupado e do valor adicionado da indústria de transformação do Paraná. Desta forma, as mudanças ocorridas no setor secundário paranaense no decorrer do decênio 1990 devem ser interpretadas como um processo de reestruturação produtiva, isto é, um esforço de adaptação ao novo cenário econômico nacional caracterizado pela intensificação da concorrência internacional.

Por fim, ressalta-se que a análise do desempenho das exportações do Paraná não permitiu identificar um processo de reprimarização de sua pauta de exportação, ou seja, verificou-se que a economia paranaense não fora contagiada pelo fenômeno “doença holandesa” no período 1990-2010. A análise da composição da pauta exportadora do Paraná mostrou um aumento da participação relativa das indústrias de alta e média-alta intensidade tecnológica. Contudo, a recente redução da participação relativa da exportação da indústria de baixa tecnologia pode ser consequência da sobreapreciação cambial, que vem ocorrendo no Brasil desde o ano de 2003.

\section{Referências}

Bresser-Pereira, Luis Carlos. (2010). "Doença holandesa e sua neutralização: uma abordagem ricardiana". In: Bresser-Pereira, Luiz Carlos. (Org.). Doença holandesa e indústria. Rio de Janeiro: FGV, cap. 5, p. 117-153.

Clark, Colin. (1980). Las condiciones del progresso economico. 2 ed. Madrid: Alianza. Instituto de Pesquisa Econômica Aplicada - IPEADATA. URL [on-line]: http://www. ipeadata.gov.br. 
Instituto Paranaense de Desenvolvimento Econômico e Social - IPARDES. (2003). Paraná: diagnóstico social e econômico. Curitiba: IPARDES.

Ministério do Desenvolvimento, Indústria e Comércio Exterior - MDIC. URL [on-line]: http://www.mdic.gov.br.

Oreiro, José Luis; Feijó, Carmem A. (2010). "Desindustrialização: conceituação, causas, efeitos e o caso brasileiro". Revista de Economia Política 30(2): 219-232.

Rowthorn, Robert; Ramaswamy, Ramana (1997). "Deindustrialization: causes and implications". IMF Working Paper.

Rowthorn, Robert; Ramaswamy, Ramana (1999). "Growth, trade e deindustrialization”. IMF Staff Papers 46(1).

Scatolin, Fábio Dória; Cruz, Márcio José Vargas; Porcile, Gabriel; Nakabashi, Luciano. (2007). "Desindustrialização? Uma análise comparativa entre Brasil e Paraná”. Indicadores Econômicos FEE 35(1): 105-120.

Suzuki, Julio Takeshi. (2009). "A indústria paranaense e o avanço tecnológico". Análise Conjuntural 31(7-8): 09-11.

Tregenna, Fiona. (2009). "Characterizing deindustrialization: an analysis of changes in manufacturing employment and output internationally". Cambrigde Journal of Economics 33(3): 433-466. 